\title{
Endoscopic submucosal dissection for early squamous cell carcinoma in the anal canal and Lugol chromoendoscopy for assessment of the lateral margin
}

\section{다)(1) $\odot$}

\author{
Authors \\ Takeshi Uozumi ${ }^{1}$, Tetsuya Sumiyoshi ${ }^{1}$, Hitoshi Kondo ${ }^{1}$, Takeyoshi Minagawa ${ }^{1}$, Ryoji Fujii ${ }^{1}$, Masahiro Yosida ${ }^{1}$, Kaho \\ Tokuchi $^{1}$, Takuya Mizukami ${ }^{1}$, Koutarou Morita ${ }^{1}$, Hideyuki Ihara ${ }^{1}$, Yutaka Okagawa ${ }^{1}$, Toshizo Takayama ${ }^{1}$, Shutaro \\ Ooiwa', Michiaki Hirayama', Yumiko Oyamada²
}

Institutions

1 Department of Gastroenterology, Tonan Hospital, Sapporo, Japan

2 Department of Pathology, Tonan Hospital, Sapporo, Japan

submitted 15.12.2017

accepted after revision 23.1.2018

\author{
Bibliography \\ DOI https://doi.org/10.1055/a-0584-7060 | \\ Endoscopy International Open 2018; 06: E1130-E1133 \\ (c) Georg Thieme Verlag KG Stuttgart · New York \\ ISSN 2364-3722
}

Corresponding author

Takeshi Uozumi, MD, Department of Gastroenterology,

Tonan Hospital, Kita 4, Nishi 7, Chuo-ku, Sapporo, Hokkaido

060-0004, Japan

Fax: +81112618692

takeshi.uozumi@tonan.gr.jp

\section{ABSTRACT}

A 66-year-old man underwent follow-up colonoscopy after colon polypectomy. The retroflexed view of the anal canal with white-light imaging revealed a whitish, slightly elevated lesion on the dentate line and an ill-defined flat lesion. A biopsy of the whitish elevation revealed squamous cell carcinoma (SCC), and endoscopic submucosal dissection (ESD) was planned. The lateral margin of the SCC was identified by spraying with Lugol's iodine, and the tumor was resected en bloc with no complications. The pathological findings were SCC in situ with parakeratosis in the whitish elevation and high-grade intraepithelial neoplasia in the ill-defined flat lesion, which exhibited a wide iodine-unstained area by chromoendoscopy. Early SCC in the anal canal is a rare gastrointestinal cancer, and Lugol chromoendoscopy helped visualize the tumor margin for ESD.

\section{Introduction}

Anal canal cancer constitutes approximately $1 \%$ of all gastrointestinal cancers, and the incidence rate of squamous cell carcinoma (SCC) in the anal canal has been increasing [1]. In recent years, early diagnosis of SCC in the anal canal has been increasing owing to advances in endoscopic equipment. However, few such cases involving endoscopic submucosal dissection (ESD) have been reported. ESD is a minimally invasive treatment for colorectal tumors without a risk of lymph node metastasis. Accurate evaluation of the extent of the tumor margin when performing ESD is important to prevent local recurrence. lodine staining facilitates detection of superficial esophageal SCC and dysplasia because mature squamous epithelial cells contain glycogen, which is stained brown by iodine. When the normal maturation of the epithelium is disturbed by dysplasia or neoplasia, the glycogen content is decreased and the lesion remains unstained. We herein report a case of early SCC in the anal canal treated by ESD, wherein Lugol chromoendoscopy was performed preoperatively to accurately assess the lateral tumor margin.

\section{Case report}

A 66-year-old man underwent follow-up colonoscopy after coIon polypectomy. A retroflex view of the anal canal with whitelight imaging (WLI) revealed a whitish, slightly elevated lesion of approximately $12 \mathrm{~mm}$ in size on the dentate line and an illdefined flat lesion extending from the dentate line to the anal canal ( $\triangleright$ Fig.1a). The extent of the flat lesion was unclear on chromoendoscopy with indigo carmine dye ( $\boldsymbol{F}$ Fig. $\mathbf{1 b}$ ) but was clearly visualized with iodine staining via Lugol chromoendoscopy. It was approximately $25 \mathrm{~mm}$ in size ( $>$ Fig. 1C). A biopsy of the whitish, slightly elevated lesion revealed SCC. The lesion 

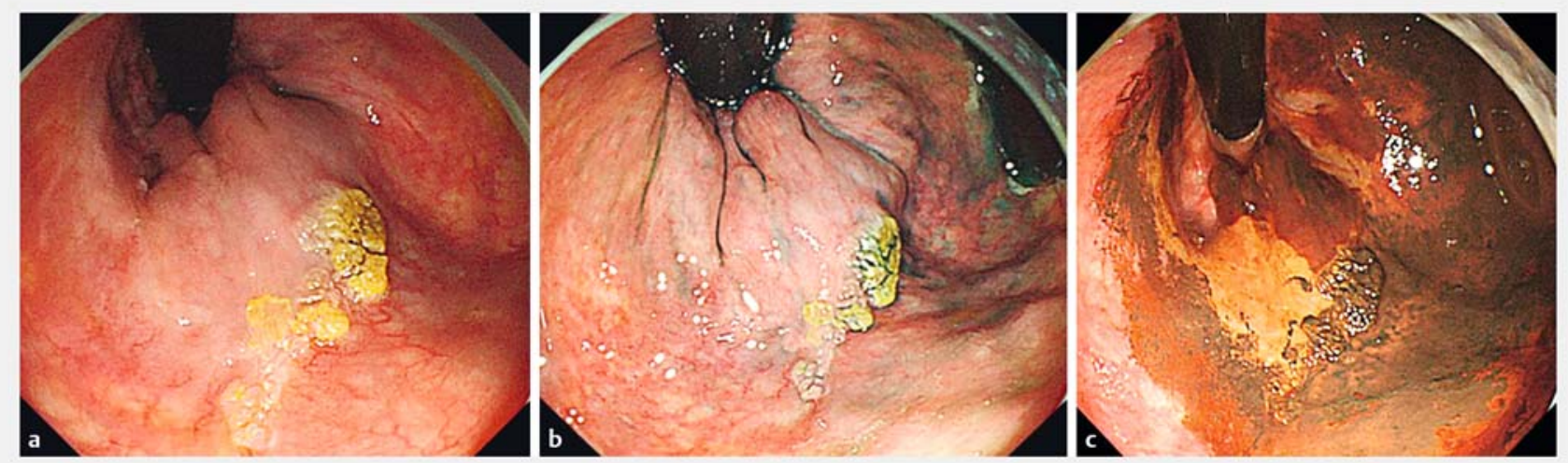

- Fig. 1 a Whitish, slightly elevated lesion in association with a flat lesion detected with WLI. The margin of the flat lesion was unclear. b Indigo carmine dye was not useful for evaluation of the margin of the ill-defined flat lesion c The margin of the ill-defined flat lesion was clearly distinguished with Lugol chromoendoscopy.

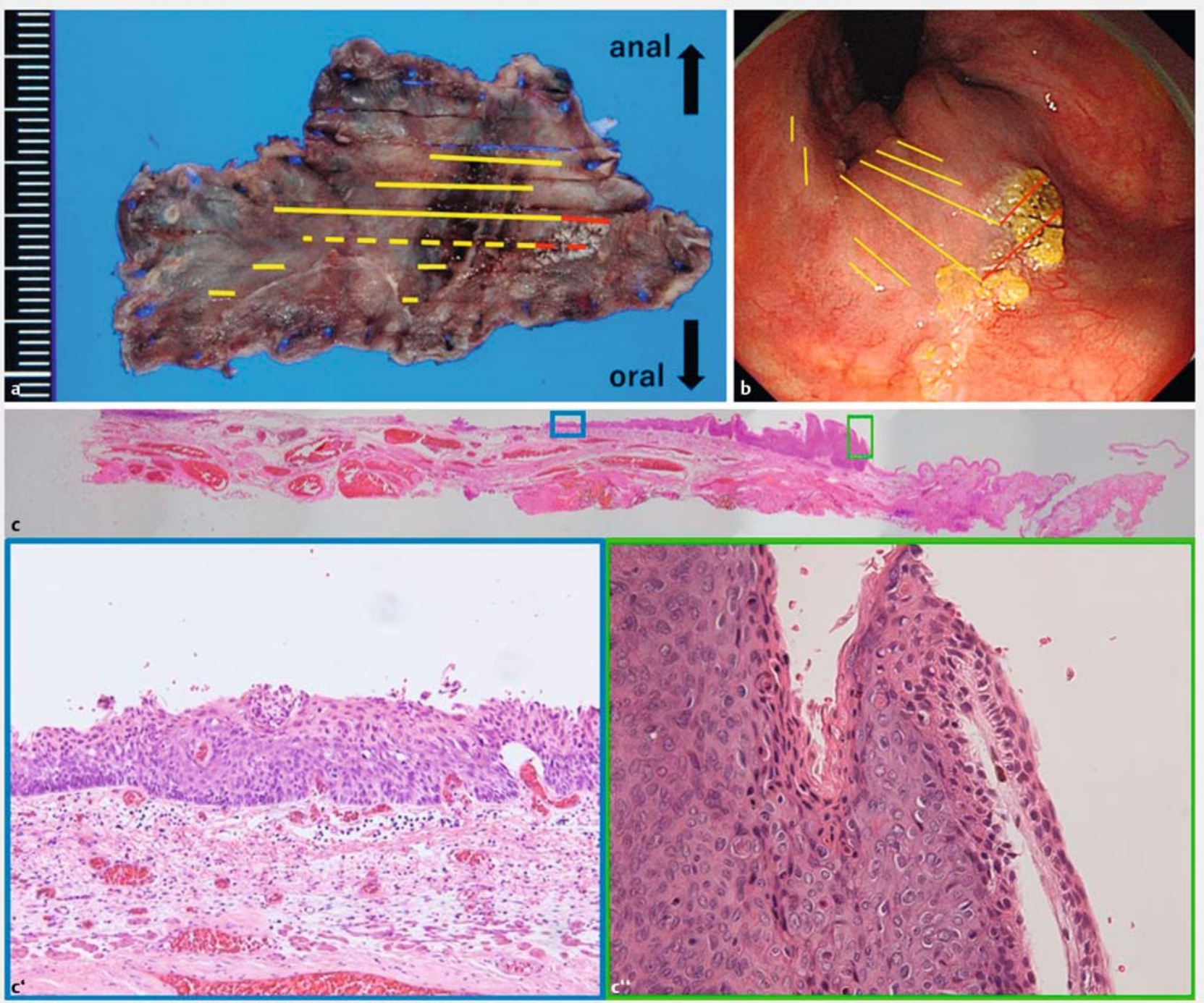

Fig. 2 a The resected specimen $(56 \times 35 \mathrm{~mm})$. The red lines indicate the area of SCC in situ. The yellow lines indicate the area of intraepithelial neoplasia. b Mapping of the retroflexed view of the anal canal. $\mathbf{c}$ The specimen is shown within the dotted line. Moderate atypia was present (blue box). Parakeratosis was observed in the superficial layer of the whitish, slightly elevated lesion (green box). 


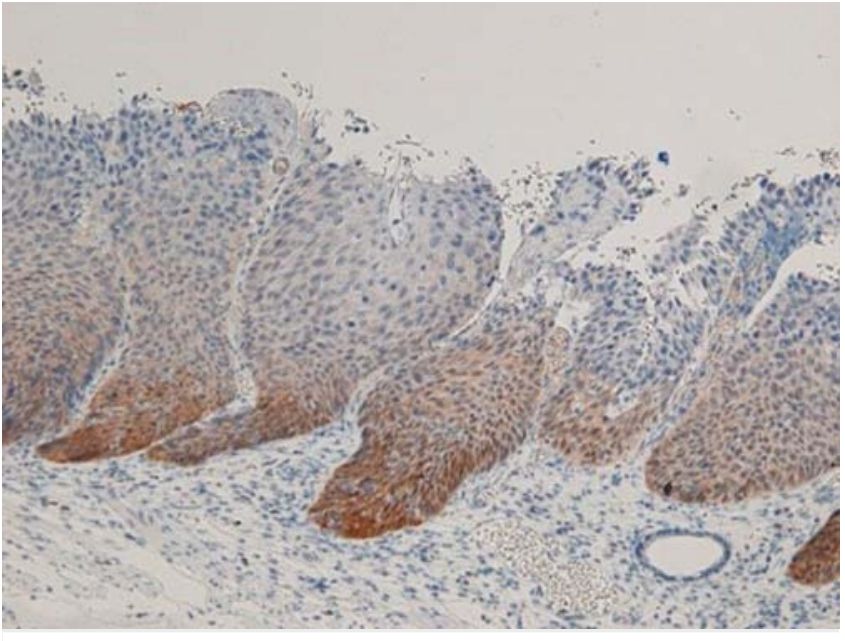

Fig. 3 p16 immunostaining of the basal layer of the tumor was positive.

appeared to be shallow on endoscopy, and computed tomography revealed no enlarged lymph nodes or distant metastasis. ESD was performed to resect the tumor en bloc. A pathological examination showed that the whitish elevated lesion was SCC in situ with parakeratosis and that the ill-defined flat lesion was high-grade intraepithelial neoplasia ( $\triangleright$ Fig.2a, b, c', and c"). The horizontal and vertical margins were free of tumor, and there was no lymphovascular invasion. p16 immunohistochemical staining was positive ( $\vee$ Fig.3), and polymerase chain reaction revealed infection by human papilloma virus 16 . The patient was discharged $9 \mathrm{~d}$ after the ESD. Computed tomography at 5-mo follow-up revealed no recurrence.

\section{Discussion}

Despite an increase in SCCs detected in the anal canal resulting from advances in endoscopic equipment and the diagnostic skill of endoscopists, SCC in situ in the anal canal is still rare.
The prognosis is related to the size of the tumor and the presence of lymph node metastases [2]. Consequently, successful curative treatment depends on early diagnosis in an early stage. Because SCC in situ in the anal canal is frequently occurs as a slightly raised or flat lesion [3], it may be easily overlooked in a forward endoscopic view. During colonoscopy, the anal region should be carefully observed in a retroflexed view.

A search of the PubMed database retrieved only 5 case reports of SCC in the anal canal to date, all of which were treated by ESD ( $\triangleright$ Table 1 ) [4-6]. One case was positive for lymphovascular invasion and was treated by chemoradiation after ESD, but no recurrences were reported over an average follow-up of 14 mo (range: $3-23 \mathrm{mo}$ ) in all these cases. ESD is accepted as a minimally invasive treatment and offers benefits with respect to the quality of life of patients. It is a potential treatment option for SCC in situ in the anal canal. Only few cases of this type have been treated by ESD, and the long-term outcome is still unclear. Because there is no evidence that ESD is useful for the treatment of anal canal carcinoma in situ, careful follow-up is necessary.

Achievement of en bloc resection when performing ESD is important to prevent local recurrence, but it may be difficult to accurately determine the extent of the tumor margin. Chromoendoscopy with indigo carmine dye has been reported for the assessment of the lateral margin of early SCC in the anal canal [7], but this technique was not useful in our case ( $\triangleright$ Fig. 1b). The use of magnifying endoscopy with narrow-band imaging has been reported for detecting early SCC in the anal canal [4-6]. However, a magnifying endoscope does not have good operability during retroflexed observation in the lower rectum, and accurate evaluation of the margin of irregularly shaped flat lesions is difficult using narrow-band imaging without magnification. In our case, Lugol chromoendoscopy improved the visualization of high-grade intraepithelial neoplasia in the anal canal, and the irregularly shaped lesion was successfully resected en bloc by ESD ( $\triangleright$ Fig. 2). The whitish, slightly elevated lesion was stained by iodine because of parakeratosis, but the margin was clearly distinguished with WLI. Lugol chromoendoscopy is a

- Table 1 Previous case reports treated with ESD.

\begin{tabular}{|c|c|c|c|c|c|c|c|c|c|c|}
\hline & Age & Sex & Form & Size & Color & Depth & $\begin{array}{l}\text { Lymphovascular } \\
\text { invasion }\end{array}$ & HPV & $\begin{array}{l}\text { Additional } \\
\text { treatment }\end{array}$ & $\begin{array}{l}\text { No recur- } \\
\text { rence }\end{array}$ \\
\hline Ito & 89 & $\mathrm{~F}$ & $\begin{array}{l}\text { Slightly } \\
\text { elevated }\end{array}$ & $10 \mathrm{~mm}$ & Whitish & Tis & Ly0, v0 & $\begin{array}{l}\text { Not avail- } \\
\text { able }\end{array}$ & - & $15 \mathrm{mo}$ \\
\hline Ito & 66 & $\mathrm{~F}$ & $\begin{array}{l}\text { Highly } \\
\text { elevated }\end{array}$ & $12 \mathrm{~mm}$ & Whitish & Tis & Ly1, v0 & $\begin{array}{l}\text { Not avail- } \\
\text { able }\end{array}$ & Chemoradiation & $23 \mathrm{mo}$ \\
\hline Tsuji & 60 & $\mathrm{~F}$ & Flat & $20 \mathrm{~mm}$ & Reddish & Tis & Ly0, v0 & $\begin{array}{l}\text { Not avail- } \\
\text { able }\end{array}$ & - & $3 \mathrm{mo}$ \\
\hline $\begin{array}{l}\text { Ta- } \\
\text { maru }\end{array}$ & 66 & $\mathrm{~F}$ & $\begin{array}{l}\text { Slightly } \\
\text { elevated }\end{array}$ & $15 \mathrm{~mm}$ & Whitish & Tis & Ly0, v0 & + & - & $12 \mathrm{mo}$ \\
\hline $\begin{array}{l}\text { Ta- } \\
\text { maru }\end{array}$ & 71 & $\mathrm{~F}$ & $\begin{array}{l}\text { Slightly } \\
\text { elevated }\end{array}$ & $25 \mathrm{~mm}$ & Whitish & Tis & Ly0, v0 & + & - & 19 mo \\
\hline $\begin{array}{l}\text { Our } \\
\text { case }\end{array}$ & 66 & $M$ & $\begin{array}{l}\text { Slightly } \\
\text { elevated }\end{array}$ & $30 \mathrm{~mm}$ & Whitish & Tis & Ly0, v0 & + & - & $6 \mathrm{mo}$ \\
\hline
\end{tabular}


simple technique that is easy to perform and can distinguish the lateral margin of dysplasia or neoplasia when used with WLI. In conclusion, patients with early SCC in the anal canal may benefit from ESD and Lugol chromoendoscopy, and careful follow-up is necessary.

\section{Competing interests}

None

\section{References}

[1] Nelson RA, Levine AM, Bernstein L et al. Changing patterns of anal canal carcinoma in the United States. J Clin Oncol 2013; 31: 1569 1575
[2] Ryan DP, Compton CC, Mayer R]. Carcinoma of the anal canal. N Engl] Med 2000; 342: $792-800$

[3] Jay N, Berry JM, Miaskowski C et al. Colposcopic characteristics and Lugol's staining differentiate anal high-grade and low-grade squamous intraepithelial lesions during high resolution anoscopy. Papillomavirus Res 2015; 1: $101-108$

[4] Tsuji S, Doyama H, Yamada S et al. Endoscopic submucosal dissection of a squamous cell carcinoma in situ in the anal canal diagnosed by magnifying endoscopy with narrow-band imaging. Clin J Gastroenterol 2014; 7: 233-237

[5] Ito T, Morita S, Shimeno $\mathrm{N}$ et al. The prospect of endoscopic submucosal dissection for early anal canal squamous cell carcinoma. Clin J Gastroenterol 2016; 9: 384-388

[6] Tamaru Y, Oka S, Tanaka $S$ et al. Early squamous cell carcinoma of the anal canal resected by endoscopic submucosal dissection. Case Rep Gastroenterol 2015; 9: 120-125

[7] Yamaguchi T, Moriya Y, Fujii T et al. Anal canal squamous-cell carcinoma in situ, clearly demonstrated by indigo carmine dye spraying. Dis Colon Rectum 2000; 43: 1161 - 1163 